\title{
Dinâmica do pH da água das chuvas em Passo Fundo, RS
}

\author{
Gilberto Rocca da Cunha(1), Anderson Santi(1), Genei Antonio Dalmago(1), \\ João Leonardo Fernandes Pires ${ }^{(1)}$ e Aldemir Pasinato(1)
} (1)Embrapa Trigo, Caixa Postal 451, CEP 99001-970 Passo Fundo, RS. E-mail: cunha@cnpt.embrapa.br, anderson@cnpt.embrapa.br,
dalmago@cnpt.embrapa.br, pires@cnpt.embrapa.br e aldemir@cnpt.embrapa.br

\begin{abstract}
Resumo - O objetivo deste trabalho foi avaliar a dinâmica do $\mathrm{pH}$ da água das chuvas em Passo Fundo, RS, de 1992 a 2007. A água foi coletada em recipiente de PVC (diâmetro de $10 \mathrm{~cm}$ ) acoplado a um pluviômetro, e as amostras foram armazenadas em congelador para posterior determinação do $\mathrm{pH}$. A dinâmica do $\mathrm{pH}$ da água foi avaliada por meio das médias mensais e anuais do $\mathrm{pH}$, da probabilidade empírica da distribuição dos valores anuais de $\mathrm{pH}$ por estação do ano e da frequência relativa acumulada do $\mathrm{pH}$. A água das chuvas incidentes na região de Passo Fundo apresentou pH acima de 5,6, que é o limite para que a chuva seja considerada ácida. A análise do período de 16 anos indicou tendência de redução do $\mathrm{pH}$ da água das chuvas em 0,023 ao ano. Nesse período, a redução foi de 6,1 para 5,8. As chuvas foram ligeiramente mais ácidas no verão e na primavera do que no outono e no inverno. Em geral, as chuvas incidentes na região não apresentaram riscos imediatos de acidificação ambiental.
\end{abstract}

Termos para indexação: chuva ácida, indicador ambiental, qualidade de água, sustentabilidade.

\section{Dynamics of rainfall pH in Passo Fundo, Rio Grande do Sul, Brazil}

\begin{abstract}
The objective of this work was to evaluate the dynamics of rainfall $\mathrm{pH}$ in Passo Fundo, RS, Brazil, from 1992 to 2007. The rainfall $\mathrm{pH}$ was monitored in $50 \mathrm{~mL}$ samples collected in a 10-cm diameter PVC tube connected to a rain gauge; samples were then stored in a freezer for later determination of $\mathrm{pH}$. The dynamics of rain water $\mathrm{pH}$ was evaluated through the annual and monthly averages of the $\mathrm{pH}$, the empirical probability of $\mathrm{pH}$ values distributed over the seasons, and the $\mathrm{pH}$ accumulated relative frequency. The rainfall events in Passo Fundo region have $\mathrm{pH}$ higher than the critical threshold $(\mathrm{pH} 5.6)$ to be considered acid rain. The analysis of a 16-year period showed reduction of the rainfall $\mathrm{pH}$ at 0.023 per year. Over that period, the average $\mathrm{pH}$ fell from 6.1 to 5.8. The rainfalls were slightly more acidic in the summer and spring than in the autumn and winter. In general, the analysis of rainfall events in the region showed no immediate risk of environmental acidification.
\end{abstract}

Index terms: acid rain, environmental index, sustainability, water quality.

\section{Introdução}

A atmosfera é constituída por uma mistura de gases, componentes sólidos e líquidos em suspensão. Tem-se observado acentuado aumento da emissão de poluentes relacionado ao crescimento industrial (Intergovernmental Panel on Climate Change, 2007). Tal fato acarreta alterações na composição química da atmosfera. Isso tem sido apontado como a causa da acidificação da água da chuva (chuva ácida) em vários locais (Migliavacca et al., 2004; Fornaro \& Gutz, 2006; Huang et al., 2008; Zhang et al., 2008).

O conceito de chuva ácida foi estabelecido pela primeira vez por Smith (1872), ao observar a relação entre o pH da água da chuva, a combustão de carvão em área industrial e os danos causados ao ecossistema pela precipitação pluvial.
Estudos indicam que o $\mathrm{pH}$ natural da água das chuvas é em torno de 5,6 (Cogbill \& Likens, 1974; Charlson \& Rodhe, 1982; Davis \& Cornwell, 1991; Hendrey, 2001; Carvalho Júnior, 2004). Esse valor ocorre naturalmente por causa do equilíbrio com a concentração de gás carbônico na atmosfera - atualmente 379 ppm (Intergovernmental Panel on Climate Change, 2007) - e é considerado como limite para a classificação de chuvas ácidas.

Com o passar dos anos, aumentaram os problemas causados por chuvas ácidas nos diversos ecossistemas e agroecossistemas mundiais. Likens \& Bormann (1974) apresentaram relações ambientais de causa e efeito, em função dos baixos valores de $\mathrm{pH}$ observados na água da chuva. Krug \& Frink (1983) descreveram a interferência da chuva ácida na acidificação do solo. Gorham (1998) discutiu os efeitos, geralmente 
negativos, da deposição ácida sobre lagos, florestas e terras baixas. Migliavacca et al. (2005b) e Huang et al. (2008) demonstraram que a atividade antrópica contribui para a acidificação da água das chuvas.

A chuva ácida é um problema global que decorre, principalmente, da emissão de óxidos de nitrogênio (NO e $\mathrm{NO}_{2}$, usualmente denominados $\mathrm{NO}_{\mathrm{x}}$ ) e de dióxido de enxofre $\left(\mathrm{SO}_{2}\right)$, advindos da queima de combustíveis fósseis (Rodhe et al., 2002; Menz \& Seip, 2004; Larssen et al., 2006; Huang et al., 2008). Kato \& Akimoto (2007) ressaltaram que o consumo de combustíveis fósseis possui relação direta com a emissão de $\mathrm{NO}_{\mathrm{x}}$ e $\mathrm{SO}_{2}$. Estudos indicam que a deposição desses gases vem ocorrendo em quantidades acima daquelas suportáveis pelo ambiente (Dentener et al., 2006), o que resulta na acidificação de 7 a $17 \%$ da área global ocupada pelos ecossistemas terrestres (Bouwman et al., 2002).

Partículas em suspensão na atmosfera têm papel fundamental na composição final da água das chuvas (Rodhe et al., 2002; Carvalho Júnior, 2004). O pH pode variar de acordo com a interação dos íons em suspensão (Fornaro \& Gutz, 2006; Pelicho et al., 2006; Huang et al., 2008; Zhang et al., 2008). A presença e a quantidade desses íons são consequência da fonte emissora e das condições de circulação do ar atmosférico (Campos et al., 2007). O pH pode variar, também, conforme a parcela da chuva amostrada num mesmo evento chuvoso, que é associada ao processo natural de limpeza da atmosfera (Mirlean et al., 2000).
Estudos que avaliam o $\mathrm{pH}$ da água das chuvas indicam que a precipitação ácida está relacionada à presença de áreas urbanas e de parques industriais entorno do ponto de medição (Mirlean et al., 2000; Flues et al., 2002; Migliavacca et al., 2004; Tresmondi et al., 2005; Pelicho et al., 2006). Locais onde predominam atividades agrícolas são menos sujeitos à formação e ocorrência de chuvas ácidas, conforme diagnosticado por Cunha \& Dalmago (2000).

O objetivo deste trabalho foi avaliar a dinâmica do $\mathrm{pH}$ da água das chuvas em Passo Fundo, RS, de 1992 a 2007.

\section{Material e Métodos}

O monitoramento do $\mathrm{pH}$ da água das chuvas foi realizado por meio de medições sistemáticas nas águas coletadas na Estação Climatológica, no campo experimental da Embrapa Trigo ( $28^{\circ} 15 ' \mathrm{~S}, 52^{\circ} 24^{\prime} \mathrm{W}$ e $684 \mathrm{~m}$ de altitude), em Passo Fundo, RS, no período de 1992 a 2007. O clima da região é subtropical úmido, tipo Cfa, conforme classificação de Köppen (Moreno, 1961). A temperatura média das mínimas domês mais frioé $8,9^{\circ} \mathrm{C}$, ea temperatura média das máximas do mês mais quente é $28,3^{\circ} \mathrm{C}$. A precipitação média anual é $1.787 \mathrm{~mm}$ (Embrapa Trigo, 2008). A precipitação mensal, de 1992 a 2007, está apresentada na Figura 1.

As medições foram realizadas nos três horários padrão de leitura das variáveis meteorológicas (12 UTC, 18 UTC e 24 UTC, ou seja, 9h, 15h e 21h, pelo horário oficial brasileiro). Os dados de precipitação foram obtidos

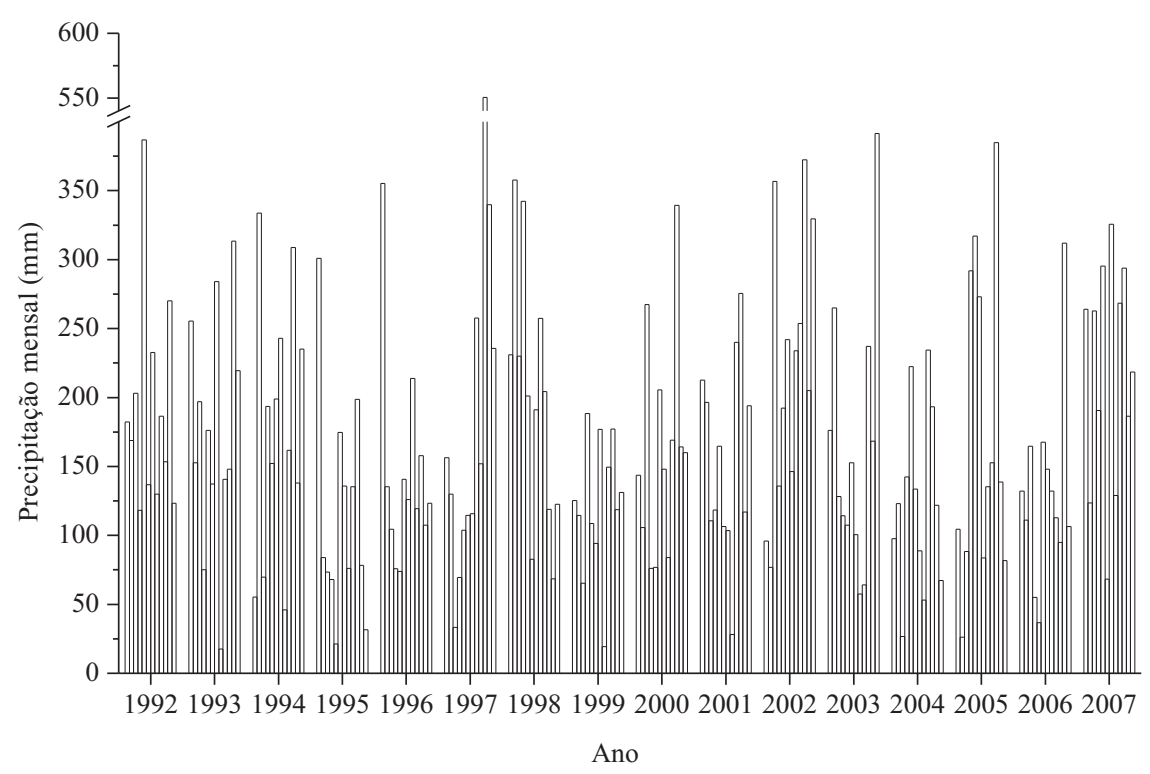

Figura 1. Precipitação mensal no período de 1992 a 2007, em Passo Fundo, RS. 
diretamente em leituras no pluviômetro Ville de Paris (com $400 \mathrm{~cm}^{2}$ de área de captação, instalado a $1,5 \mathrm{~m}$ acima do solo) da Estação Climatológica. Para o monitoramento do $\mathrm{pH}$, foi utilizado coletor de PVC com diâmetro de $10 \mathrm{~cm}$, acoplado ao pluviômetro. A cada chuva, uma alíquota de até $50 \mathrm{~mL}$ de água foi colhida e imediatamente congelada, para posterior determinação do $\mathrm{pH}$.

Após o descongelamento das amostras, realizou-se a determinação dopH por meio de potenciômetro de eletrodos combinados, com precisão de 0,01 , calibrado previamente em solução tampão com pH 4 e pH 7. Os resultados médios mensais de $\mathrm{pH}$, de 1992 a 2007, foram calculados pela concentração média volumétrica/altura (CMV) (Tresmondi et al., 2005). A CMV foi calculada conforme a equação:

$\mathrm{CMV}_{\left[\mathrm{H}^{+}\right]}=\left[\Sigma\left(\left[\mathrm{H}^{+}\right] \mathrm{i} \times \mathrm{Vi}\right)\right] / \Sigma \mathrm{Vi}$,

em que: CMV é a concentração média volumétrica/altura de $\left[\mathrm{H}^{+}\right] ;\left[\mathrm{H}^{+}\right]=10^{(-\mathrm{pH})}$; $\left[\mathrm{H}^{+}\right]$i é a concentração do $\mathrm{H}^{+}$medida no evento i; Vi é a altura de precipitação ( $\mathrm{mm}$ ) no evento i.

As coletas de água e os valores de $\mathrm{pH}$ foram classificados em "primeiro recolhimento" ou "segundo recolhimento". Como primeiro recolhimento, foi considerada a água coletada da primeira chuva do período, ou seja, o recolhimento de água de chuvas sem registro de precipitação no horário padrão de coleta anterior. Como segundo recolhimento, foi considerada a água coletada da chuva consecutiva ao primeiro recolhimento.

Durante os 16 anos de estudo, foram computadas 4.186 leituras no pluviômetro, o que implica 2.413 eventos de chuva (um evento de chuva corresponde a pelo menos uma precipitação, computada durante as três leituras diárias). O número máximo de leituras de $\mathrm{pH}$ utilizadas para a análise dos dados foi 1.927, porque, em alguns eventos de precipitação, não houve possibilidade de se coletar a amostra ou o volume de água amostrado foi insuficiente para a determinação do $\mathrm{pH}$.

Para os valores de $\mathrm{pH}$ da água das chuvas, foram calculadas as médias anuais, médias mensais anuais $\mathrm{e}$ as médias mensais do período, com o respectivo desviopadrão. A probabilidade empírica da distribuição dos valores anuais de $\mathrm{pH}$ da água das chuvas foi discriminada por estação do ano e analisada por meio do diagrama de caixas (boxplot). Quanto às médias anuais e para as estações do ano, foi calculada a frequência relativa acumulada, tendo-se considerado, separadamente, o primeiro e o segundo recolhimento de chuvas. As estações do ano foram classificadas de acordo com o critério climatológico: verão (dezembro, janeiro e fevereiro), outono (março, abril e maio), inverno (junho, julho e agosto) e primavera (setembro, outubro e novembro). A análise de regressão e o diagrama de caixas foram realizados mediante a utilização do programa estatístico OriginPro 8.0 (OriginLab, 2008).

\section{Resultados e Discussão}

De acordo com a classificação do $\mathrm{pH}$ da água das chuvas em normal (igual ou maior que 5,6), levemente ácido (de 5 a 5,6) e ácido (menor que 5), o pH mensal oscilou entre ácido e normal (Tabela 1), o que indica grande variabilidade no período de estudo. Essa variação foi maior nos meses de janeiro e abril (desviopadrão de 0,9 ). Os valores de $\mathrm{pH}$ médio anual e mensal ficaram acima de 5,6, o que demonstra predominância de chuvas não ácidas para a região de Passo Fundo.

Tabela 1. Valores médios mensais do pH da água das chuvas no período de 1992 a 2007, em Passo Fundo, RS.

\begin{tabular}{|c|c|c|c|c|c|c|c|c|c|c|c|c|c|}
\hline \multirow[t]{2}{*}{ Ano } & \multicolumn{12}{|c|}{ Mês } & \multirow[t]{2}{*}{ Média } \\
\hline & Jan. & Fev. & Mar. & Abr. & Maio & Jun. & Jul. & Ago. & Set. & Out. & Nov. & Dez. & \\
\hline 1992 & - & 6,5 & 7,1 & 6,3 & 6,4 & 6,2 & 6,2 & 6,2 & 6,2 & 6,1 & 6,0 & 6,0 & 6,3 \\
\hline 1993 & 6,5 & 5,8 & 6,0 & 6,1 & 6,1 & 5,8 & 6,0 & 5,9 & 5,8 & 5,9 & 5,9 & 6,1 & 6,0 \\
\hline 1994 & 7,1 & 6,0 & 6,0 & 6,5 & 6,3 & 6,3 & 6,3 & 6,1 & 6,3 & 6,0 & 6,0 & 6,1 & 6,3 \\
\hline 1995 & 7,2 & 6,0 & 6,0 & 5,9 & 6,0 & 7,5 & 6,3 & 5,9 & 6,0 & 5,9 & 6,0 & 6,0 & 6,2 \\
\hline 1996 & 6,0 & 6,0 & 6,2 & 6,0 & 6,0 & 6,0 & 6,1 & 5,9 & 5,9 & 5,9 & 6,0 & 6,1 & 6,0 \\
\hline 1997 & 6,2 & 6,2 & 6,0 & 6,2 & 6,1 & 6,1 & 6,1 & 6,0 & 6,0 & 6,0 & 5,9 & 6,0 & 6,1 \\
\hline 1998 & 6,0 & - & - & - & 6,0 & 8,0 & 5,5 & 3,8 & 4,7 & 6,3 & 6,2 & 5,7 & 5,8 \\
\hline 1999 & 3,5 & 4,1 & 5,2 & 5,1 & 6,5 & 7,1 & 6,3 & 6,4 & 6,4 & 5,1 & - & 5,5 & 5,6 \\
\hline 2000 & 6,1 & 5,6 & 5,6 & 3,0 & 6,5 & 5,6 & 6,0 & 5,3 & 5,1 & 5,2 & 5,0 & 4,1 & 5,3 \\
\hline 2001 & 6,1 & 6,0 & 4,7 & 5,9 & 5,3 & - & 5,7 & 5,6 & 5,2 & 5,5 & 4,1 & - & 5,4 \\
\hline 2002 & 5,6 & 5,5 & 5,8 & 5,5 & 6,0 & 6,2 & 5,6 & 5,9 & 5,8 & 5,7 & 5,4 & 5,5 & 5,7 \\
\hline 2003 & 5,3 & 5,6 & 6,5 & 6,2 & - & 5,4 & 5,1 & 5,5 & 5,0 & 5,7 & 5,6 & 5,8 & 5,6 \\
\hline 2004 & 6,5 & 5,8 & 7,0 & 6,3 & 6,0 & 6,4 & 6,1 & 6,5 & 5,9 & 5,3 & 6,4 & 5,9 & 6,2 \\
\hline 2005 & 5,1 & 6,4 & 5,7 & 5,6 & 5,7 & 5,8 & 6,0 & - & - & 5,5 & 6,9 & 7,1 & 6,0 \\
\hline 2006 & 6,0 & - & 6,1 & - & - & - & 5,9 & 6,3 & 6,7 & 6,0 & 5,4 & 5,4 & 6,0 \\
\hline 2007 & 5,6 & 5,9 & 5,8 & 5,7 & 5,8 & 6,0 & 6,2 & 5,7 & 5,8 & 5,9 & 6,0 & 6,1 & 5,9 \\
\hline Média $^{(1)}$ & 5,9 & 5,8 & 6,0 & 5,7 & 6,1 & 6,3 & 6,0 & 5,8 & 5,8 & 5,7 & 5,8 & 5,8 & 5,9 \\
\hline Desvio-padrão & 0,9 & 0,6 & 0,6 & 0,9 & 0,3 & 0,7 & 0,3 & 0,6 & 0,6 & 0,3 & 0,6 & 0,6 & 0,3 \\
\hline
\end{tabular}

${ }^{(1)}$ Média aritmética dos valores de $\mathrm{pH}$ ponderados pelo volume. 
Esses resultados diferem dos obtidos por Flues et al. (2003) e Migliavacca et al. (2005a), para o Sul do Brasil, onde prevaleceram chuvas levemente ácidas. É possível que esta diferença esteja relacionada ao local de estudo. Este trabalho foi realizado em uma região predominantemente agrícola, enquanto os estudos de Flues et al. (2003) e Migliavacca et al. (2005a) foram feitos em locais com grandes processos de produção e consumo de energia termoelétrica.

Além da menor emissão de elementos que provocam a acidificação das chuvas, em comparação a processos industriais, a atividade agrícola ocasiona maior emissão de $\mathrm{NH}_{3}$ e $\mathrm{NH}_{4}^{+}$(Rodhe et al., 2002; Erisman et al., 2008), que constituem fatores de neutralização da acidez da água das chuvas (Pelicho et al., 2006; Zhang et al., 2008). Isso pode ter contribuído para a obtenção de $\mathrm{pH}$ acima do limite crítico no presente trabalho.

A oscilação do $\mathrm{pH}$ durante os meses está apresentada na Figura 2A. Observa-se, pela equação ajustada $(\mathrm{p}<0,0001)$,
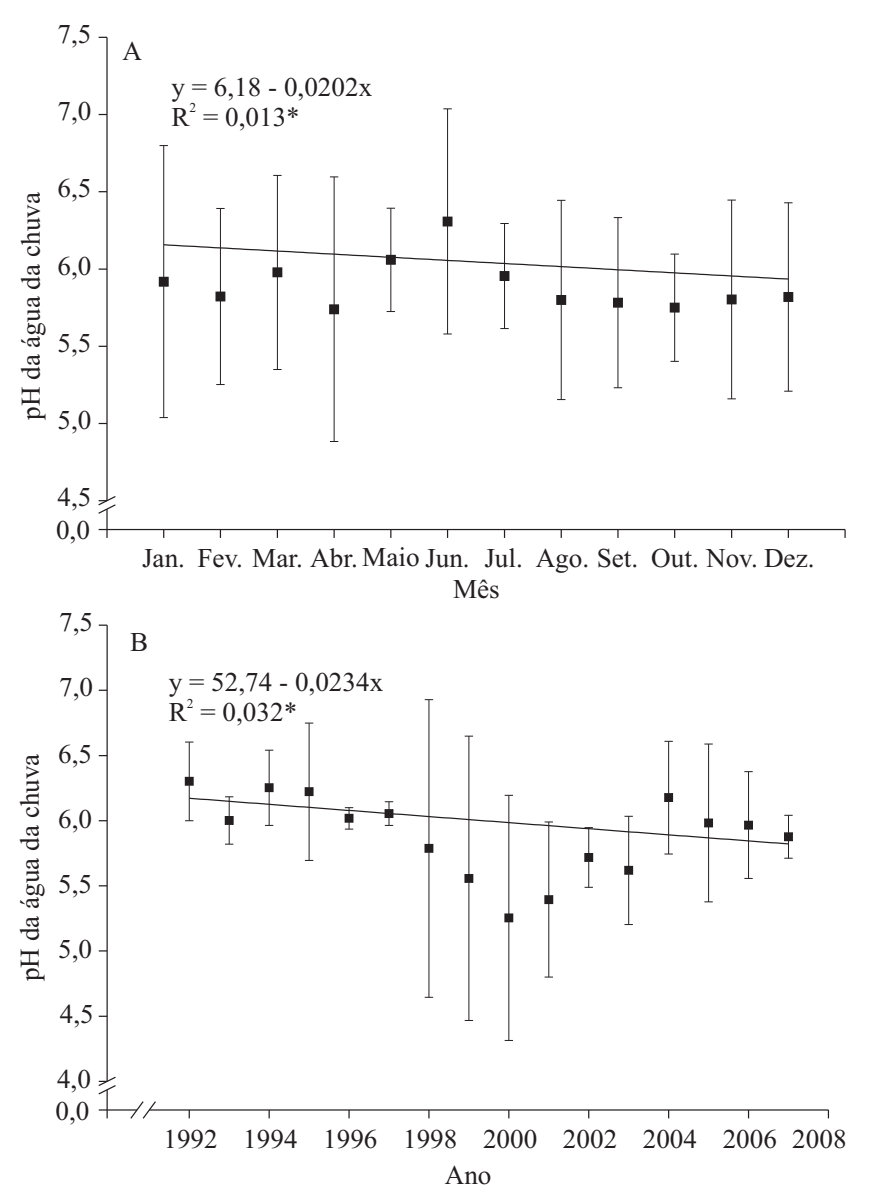

Figura 2. Médias mensais (A) e anuais (B) do $\mathrm{pH}$ da água das chuvas, com respectivos desvios-padrão, no período de 1992 a 2007, em Passo Fundo, RS. a tendência de redução do $\mathrm{pH}$ de janeiro para dezembro, com taxa de 0,020 valor de $\mathrm{pH}$ ao mês. Essa variação é distinta daquela apresentada em outras partes do Rio Grande do Sul, onde Mirlean et al. (2000) constataram leve inclinação de redução de $\mathrm{pH}$ somente para os meses de dezembro a junho. Entretanto, no presente trabalho, a média mensal do $\mathrm{pH}$ esteve sempre acima do limite crítico de 5,6, o que indica que a precipitação não constituiu fator de risco para o meio ambiente durante o período avaliado.

Verificou-se tendência anual significativa $(\mathrm{p}<0,0001)$ de redução do $\mathrm{pH}$ (Figura $2 \mathrm{~B})$. A taxa de decréscimo foi de 0,023 valor de $\mathrm{pH}$ ao ano, com redução de 0,36 valor de pH no período. Em 2002, o pH médio da água das chuvas que incidiram em Passo Fundo foi 6,1, e 16 anos depois foi 5,8. A redução ocorrida nesse período correspondeu a $60 \%$ da diferença entre o valor inicial do $\mathrm{pH}$ e o limite considerado crítico. Isso indica que, a continuar essa tendência, em alguns anos haverá predominância de chuvas levemente ácidas na região. Os valores observados, no entanto, são superiores aos verificados em outros locais no Brasil (Flues, 2003; Migliavacca et al., 2005b; Tresmondi et al., 2005) e em outros países (Swinbanks, 1989; Marín et al., 2001; Larssen et al., 2006; Huang et al., 2008).

A tendência observada no presente trabalho é oposta àquela apresentada por Fornaro \& Gutz (2006), que avaliaram o pH da água das chuvas na região metropolitana de São Paulo. Esses autores verificaram aumento de $\mathrm{pH}$ com o tempo, o que pode indicar mudança nos padrões de emissão e deposição de poluentes, em consequência das fontes geradoras. Mudanças quantitativas nos padrões de emissão de elementos geradores de chuva ácida, geralmente, estão relacionadas ao incremento da industrialização e provocam redução do $\mathrm{pH}$ da água das chuvas, principalmente em áreas com predominância agrícola (Flues et al., 2002).

É importante identificar o que está causando a redução do $\mathrm{pH}$ da água das chuvas em Passo Fundo. O somatório das diversas fontes brasileiras de emissão de poluentes poderá traduzir-se no agravamento da incidência de chuva ácida no país. Isto demandaria elevados gastos com a recuperação ambiental. Como exemplo, a crescente 
industrialização em países desenvolvidos (Likens \& Bormann, 1974) e a agricultura europeia anterior à década de 90 , com emissão significativa de $\mathrm{NH}_{3}$, contribuíram para o aumento da incidência de chuvas ácidas (Erisman et al., 2008), com pH de até 2,1 (Likens \& Bormann, 1974). Atualmente, nesses locais, são investidos bilhões de dólares ao ano em programas para a contenção das emissões de dióxido de enxofre e óxidos de nitrogênio, que são os principais precursores da acidez da água das chuvas (Ghestnut \& Mills, 2005).

A probabilidade empírica da variação do $\mathrm{pH}$ da água das chuvas, em cada estação do ano, está apresentada na Figura 3. A tendência central indica que as águas das chuvas de verão e primavera têm $\mathrm{pH}$ ligeiramente inferior àquelas de outono e inverno, embora, em todos os casos, o valor de $\mathrm{pH}$ seja superior ao limite crítico. Estudos evidenciam que valores menores de $\mathrm{pH}$ ocorrem sobretudo no verão (Marín et al., 2001), provavelmente em consequência da máxima insolação, que favorece a gênese de compostos ácidos na atmosfera, principalmente pela oxidação do óxido de enxofre (Rúa et al., 1998). Na região de Passo Fundo, também a insolação máxima ocorre no verão (Embrapa Trigo, 2008), o que indica, talvez, influência dessa circunstância nos menores valores de pH nessa estação do ano.

A disposição espacial dos dados, observada pela análise dos quartis inferiores, indica que durante

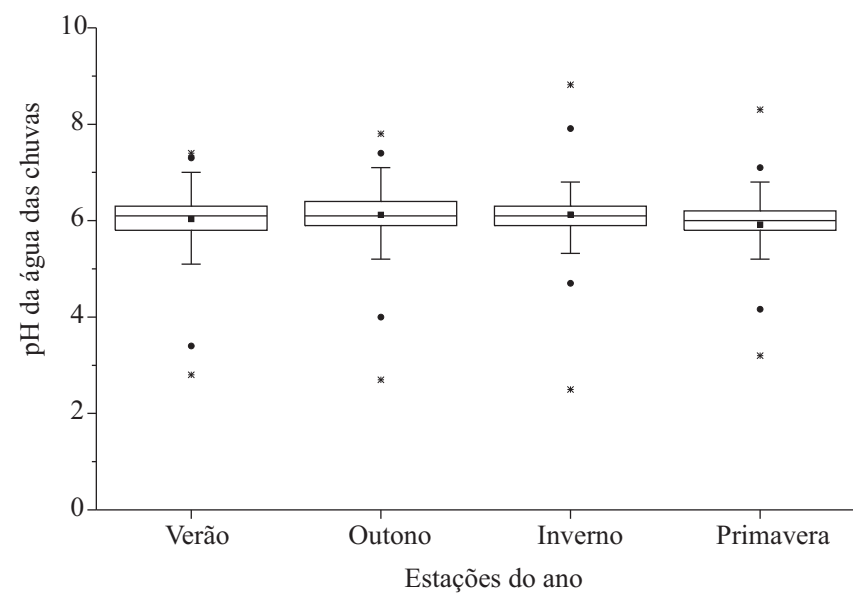

Figura 3. Diagrama em caixa da distribuição do $\mathrm{pH}$ da água das chuvas nas estações do ano, no período de 1992 a 2007 , em Passo Fundo, RS. o período estudado no mínimo $75 \%$ das chuvas apresentaram valores de $\mathrm{pH}$ acima do limite crítico (média de 5,8 no verão e primavera e 5,9 no outono e inverno). Contribuiu para esses indicadores o fato de a região e seu entorno não apresentarem um grande parque industrial que, segundo Flues et al. (2003) e Migliavacca et al. (2005b), é um fator de elevada emissão de poluentes que podem estar associados à formação de chuvas ácidas. Entretanto, como na região predominam as atividades agrícolas, as quais emitem compostos que ocasionam aumento do $\mathrm{pH}$ da água das chuvas (Zhang et al., 2008), é possível que isso tenha contribuído para a manutenção dos valores de $\mathrm{pH}$ acima do limite crítico de 5,6.

A frequência relativa acumulada do $\mathrm{pH}$ da água das chuvas, do primeiro e segundo recolhimentos, está apresentada na Figura 4. Conforme a classificação preconizada na metodologia, observase que, para o primeiro e segundo recolhimentos, respectivamente, 16 e $17 \%$ dos valores de $\mathrm{pH}$ registrados são inferiores a 5,6, e apenas em torno de $5 \%$ dos valores de $\mathrm{pH}$ caracterizam chuvas ácidas. Além disso, parece não haver diferença de $\mathrm{pH}$ entre os recolhimentos, o que indica que o processo de limpeza atmosférica, proporcionado pela primeira chuva, provavelmente não interferiu na composição da água de forma a expressar mudanças nos padrões de acidez. Todavia, resultados obtidos por Mirlean et al. (2000)

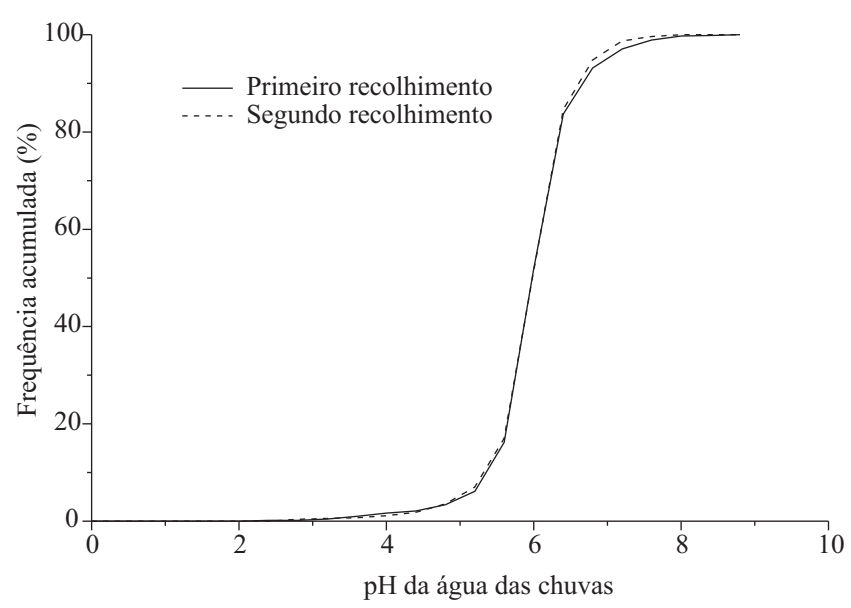

Figura 4. Frequência relativa acumulada de valores do $\mathrm{pH}$ da água das chuvas no primeiro e segundo recolhimentos, no período de 1992 a 2007, em Passo Fundo, RS. 
demonstraram aumento de $\mathrm{pH}$, a partir da segunda parcela de chuva coletada, atribuído à remoção dos constituintes atmosféricos causadores da acidez na precipitação da primeira parcela de chuva. Outros fatores do ambiente também interferem no $\mathrm{pH}$ da água das chuvas. Assim, a deposição e transporte de elementos pelas chuvas (como amônia, sais, elementos de acidez da água etc.) são influenciados por emissão local, altitude em relação ao nível do mar e condições meteorológicas como campo de vento, tamanho da gota de chuva e altura da camada de mistura (Baron \& Denning, 1993), além da origem da chuva, continental ou marinha (Kelly et al., 2009).

Considerando-se o pH das chuvas intraestações, observa-se tendência semelhante na frequência acumulada para o primeiro e segundo recolhimentos, nas quatro estações do ano (Figura 5). Entretanto, a frequência de chuvas com $\mathrm{pH}$ inferior ao limite crítico é ligeiramente maior na primavera e no verão (média aproximada de $15 \%$ ), em comparação ao outono e ao inverno (média aproximada de 10\%). Esses resultados podem ser considerados satisfatórios, principalmente quando comparados ao estudo de Migliavacca et al. (2004), que demonstraram que até $87 \%$ das chuvas apresentaram $\mathrm{pH}$ entre 5 e 5,5. Em todas as estações do ano, independentemente do recolhimento, mais de $80 \%$ das chuvas situaramse na faixa de $\mathrm{pH}$ normal, entre 5,6 e 7,2.

A análise dos dados indica que a região de Passo Fundo não apresenta incidência significativa de chuva ácida, mas a variação estacional demonstra pequena tendência de redução do $\mathrm{pH}$ da água das chuvas na primavera e no verão.
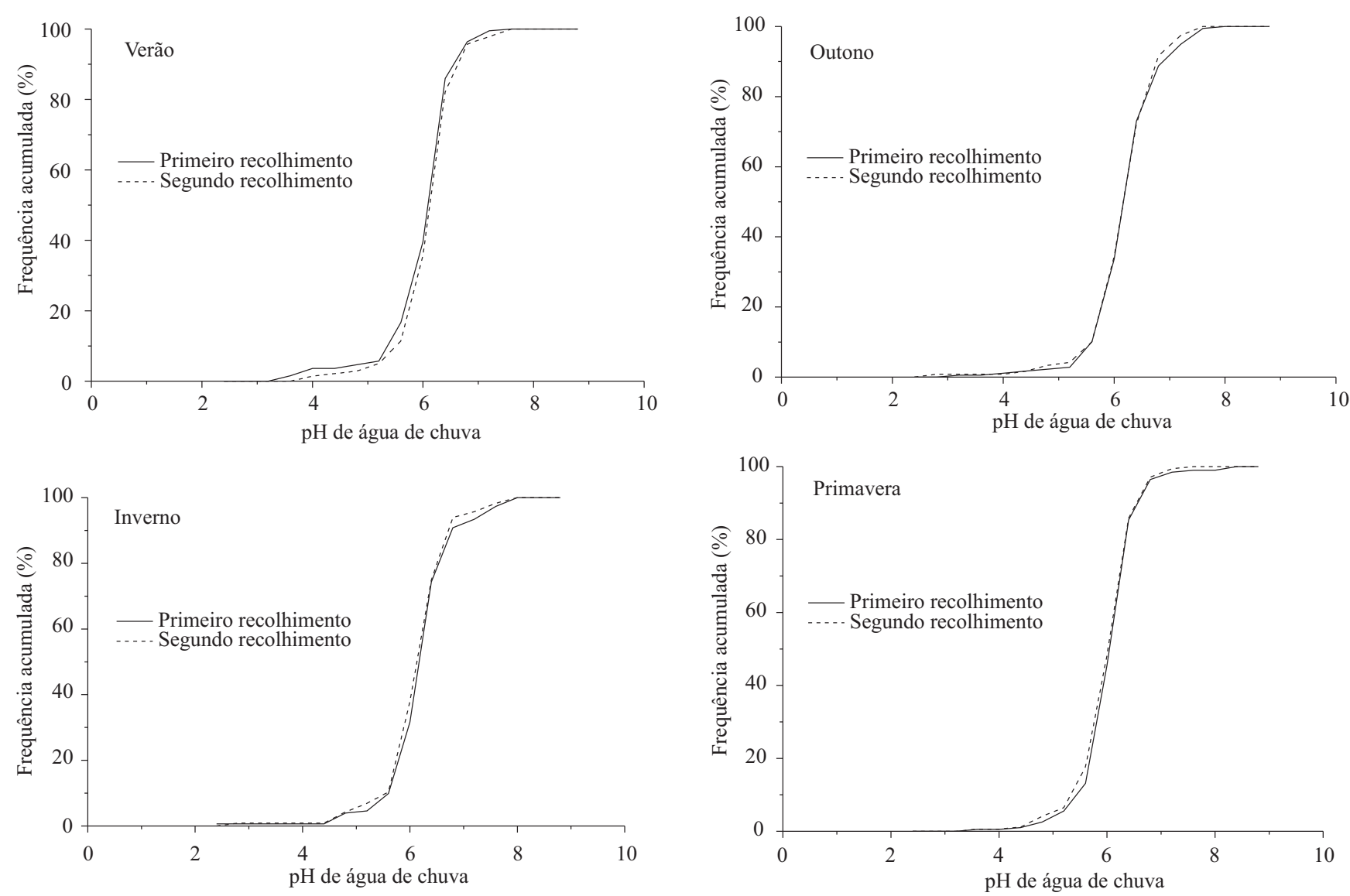

Figura 5. Frequência relativa acumulada dos valores do $\mathrm{pH}$ da água das chuvas, nas estações do ano, para o primeiro e segundo recolhimentos, no período de 1992 a 2007, em Passo Fundo, RS. 


\section{Conclusões}

1. As chuvas que incidem em Passo Fundo, RS, apresentam água com $\mathrm{pH}$ médio de 5,9, considerado acima do limite crítico de classificação de chuva ácida.

2. Há tendência de redução do $\mathrm{pH}$ da água das chuvas incidentes em Passo Fundo, com taxa aproximada de 0,02 valor de $\mathrm{pH}$ ao ano.

3. A frequência da água de chuvas com $\mathrm{pH}$ abaixo do limite crítico de classificação de chuva ácida é maior no verão e na primavera.

\section{Referências}

BARON, J.; DENNING, A.S. The influence of mountain meteorology on precipitation chemistry at low and high elevations of the Colorado Front Range, USA. Atmospheric Environment Part A - General Topics, v.27, p.2337-2349, 1993.

BOUWMAN, A.F.; VAN VUUREN, D.P.; DERWENT, R.G.; POSCH, M. A global analysis of acidification and eutrophication of terrestrial ecosystems. Water, Air and Soil Pollution, v.141, p.349-382, 2002.

CAMPOS, V.P.; COSTA, A.C.A.; TAVARES, T.M. Partial neutralization of rain by seaspray: the case of Recôncavo, Bahia Brazil. Journal of Environmental Management, v.84, p.204-212, 2007.

CARVALHO JÚNIOR, V.N. de. Deposição atmosférica e composição química da água de chuva. Revista Tecnologia, v.25, p.61-71, 2004.

CHARLSON, R.J.; RODHE, H. Factors controlling the acidity of natural rainwater. Nature, v.295, p.683-685, 1982.

COGBILL, C.V.; LIKENS, G.E. Acid precipitation in the Northeastern United States. Water Resources Research, v.10, p.1133-1137, 1974.

DAVIS, M.L.; CORNWELL, D.A. Introduction to environmental engineering. 2.ed. New York: McGraw-Hill, 1991. 822p.

DENTENER, F.; DREVET, J.; LAMARQUE, J.F.; BEY, I.; EICKHOUT, B.; FIORE, A.M.; HAUGLUSTAINE, D.; HOROWITZ, L.W.; KROL, M.; KULSHRESTHA, U.C.; LAWRENCE, M.; GALY-LACAUX, C.; RAST, S.; SHINDELL, D.; STEVENSON, D.; VAN NOIJE, T.; ATHERTON, C.; BELL, N.; BERGMAN, D.; BUTLER, T.; COFALA, J.; COLLINS, B.; DOHERTY, R.; ELLINGSEN, K.; GALLOWAY, J.; GAUSS, M.; MONTANARO, V.; MULLER, J.F.; PITARI, G.; RODRIGUEZ, J.; SANDERSON, M.; SOLMON, F.; STRAHAN, S.; SCHULTZ, M.; SUDO, K.; SZOPA, S.; WILD, O. Nitrogen and sulfur deposition on regional and global scales: a multimodel evaluation. Global Biogeochemical Cycles, v.20, 2006. Http://dx.doi. org/10.1029/2005GB002672.

EMBRAPA TRIGO. Normais climatológicas (1961-1990): Passo Fundo - RS. Disponível em: <http://www.cnpt.embrapa.br/ pesquisa/agromet/app/principal/normais.php>. Acesso em: 22 ago. 2008.
ERISMAN, J.W.; BLEEKER, A.; HENSEN, A.; VERMEULEN, A. Agricultural air quality in Europe and the future perspectives. Atmospheric Environment, v.42, p.3209-3217, 2008.

FLUES, M.; HAMA, P.; FORNARO, A. Avaliação do nível da vulnerabilidade do solo devido à presença de termelétrica a carvão (Figueira, PR - Brasil). Química Nova, v.26, p.479-483, 2003.

FLUES, M.; HAMA, P.; LEMES, M.J.L.; DANTAS, E.S.K.; FORNARO, A. Evaluation of the rainwater acidity of a rural region due to a coal-fired power plant in Brazil. Atmospheric Environment, v.36, p.2397-2404, 2002.

FORNARO, A.; GUTZ, I.G.R. Wet deposition and related atmospheric chemistry in the São Paulo metropolis, Brazil. Part 3: trends in precipitation chemistry during 1983-2003. Atmospheric Environment, v.40, p.5893-5901, 2006.

GHESTNUT, L.G.; MILLS, D.M. A fresh look at the benefits and costs of the US acid rain program. Journal of Environmental Management, v.77, p.252-266, 2005.

GORHAM, E. Acid deposition and its ecological effects: a brief history of research. Environmental Science \& Policy, v.1, p.153-166, 1998.

HENDREY, G.R. Acid rain and deposition. In: LEVIN, S.A. (Ed.). Encyclopedia of Biodiversity. San Diego: Academic Press, 2001. v.1. p.1-15.

HUANG, Y.L.; WANG, Y.L.; ZHANG, L.P. Long-term trend of chemical composition of wet atmospheric precipitation during 1986-2006 at Shenzhen City, China. Atmospheric Environment, v.42, p.3740-3750, 2008.

INTERGOVERNMENTAL PANEL ON CLIMATE CHANGE. Climate change 2007: the physical science basis: summary for Policymakers. Paris: IPCC, 2007. 21p. Contribution of Working Group I to the Fourth Assessment Report of the Intergovernmental Panel on Climate Change.

KATO, N.; AKIMOTO, H. Anthropogenic emissions of $\mathrm{SO}_{2}$ and $\mathrm{NO}_{\mathrm{x}}$ in Asia: emission inventories. Atmospheric Environment, v.41, p.171-191, 2007.

KELLY, V.R.; WEATHERS, K.C.; LOVETT, G.M.; LIKENS, G.E. Effect of climate change between 1984 and 2007 on precipitation chemistry at a site in Northeastern USA. Environmental Science \& Technology, 2009. Disponível em: <http://pubs.acs.org/doi/ full/10.1021/es8033473>. Acesso em: 22 abr. 2009.

KRUG, C.E.; FRINK, C.R. Acid rain on acid soil: a new perspective. Science, v.221, p.520-525, 1983.

LARSSEN, T.; LYDERSEN, E.; TANG, D.; HE, Y.; GAO, J.; LIU, H.; DUAN, L.; SEIP, H.M.; VOGT, R.D.; MULDER, J.; SHAO, M.; WANG, Y.; SHANG, H.; ZHANG, X.; SOLBERG, S.; AAS, W.; OKLAND, T.; EILERTSEN, O.; ANGELL, V.; LI, Q.; ZHAO, D.; XIANG, R.; XIAO, J.; LUO, J. Acid rain in China. Environmental Science \& Technology, v.40, p.418-425, 2006.

LIKENS, G.E.; BORMANN, F.H. Acid rain: a serious regional environmental problem. Science, v.184, p.1176-1179, 1974.

MARÍN, E.; LAVÍN, N.; HERÁNDEZ, E.; RÚA, A. Análisis de la acidez de la precipitación en la Península Ibéria. Finisterra, v.XXXVI, p.103-113, 2001. 
MENZ, F.C.; SEIP, H.M. Acid rain in Europe and the United States: an update. Environmental Science \& Policy, v.7, p.253-265, 2004.

MIGLIAVACCA, D.M.; TEIXEIRA, E.C.; MACHADO, A.C. de M.; PIRES, M.R. Composição da precipitação atmosférica no Sul do Brasil - estudo preliminar. Química Nova, v.28, p.371-379, 2005a.

MIGLIAVACCA, D.; TEIXEIRA, E.C.; PIRES, M.; FACHEL, J. Study of chemical elements in atmospheric precipitation in South Brazil. Atmospheric Environment, v.38, p.1641-1656, 2004.

MIGLIAVACCA, D.; TEIXEIRA, E.C.; WIEGAND, F.; MACHADO, A.C.M.; SANCHEZ, J. Atmospheric precipitation and chemical composition of an urban site, Guaíba hydrographic basin, Brazil. Atmospheric Environment, v.39, p.1829-1844, 2005b.

MIRLEAN, N.; VANZ, A.; BAISCH, P. Níveis e origem da acidificação das chuvas na região do Rio Grande, RS. Química Nova, v.23, p.590-593, 2000.

MORENO, J.A. Clima do Rio Grande do Sul. Porto Alegre: Secretaria da Agricultura, Diretoria de Terras e Colonização, Seção de Geografia, 1961. 46p.

ORIGINLAB. OriginPro 8.0 SR4. Northampton: OriginLab, 2008. 1 CD-ROM.
PELICHO, A.F.; MARTINS, L.D.; NOMI, S.N.; SOLCI, M.C. Integrated and sequential bulk and wet-only samplings of atmospheric precipitation in Londrina, South Brazil (1998-2002). Atmospheric Environment, v.40, p.6827-6835, 2006.

RODHE, H.; DENTENER, F.; SCHULZ, M. The global distribution of acidifying wet deposition. Environmental Science \& Technology, v.36, p.4382-4388, 2002.

RÚA, A.; GIMENO, L.; HERNÁNDEZ, E. Trends and seasonal variation of $\mathrm{SO}_{2}, \mathrm{NO}_{\mathrm{x}}, \mathrm{SO}_{4}{ }^{2-}$ and $\mathrm{NO}_{3}{ }^{-}$concentrations in the air of the spanish EMEP Stations. Toxicological and Environmental Chemistry, v.65, p.153-161, 1998.

SMITH, R.A. Air and rain: the beginnings of a chemical climatology. London: Longmans-Green, 1872.600p.

SWINBANKS, D. Acid-rain: China blamed for high $\mathrm{pH}$. Nature, v.340, p.671, 1989.

TRESMONDI, A.C.C. de L.; TOMAZ, E.; KRUSCHE, A.V. Avaliação de pH e composição iônica das águas de chuva em Paulínia-SP. Engenharia Ambiental, v.2, p.70-84, 2005.

ZHANG, Y.; WU, S.Y.; KRISHNAN, S.; WANG, K.; QUEEN, A.; ANEJA, V.P.; ARYA, S.P. Modeling agricultural air quality: current status, major challenges, and outlook. Atmospheric Environment, v.42, p.3218-3237, 2008.

Recebido em 4 de novembro de 2008 e aprovado em 31 de março de 2009 